\title{
Enantioselective Rhodium Enolate Protonations. A New Methodology for the Synthesis of $\beta^{2}$-Amino Acids
}

\author{
Mukund P. Sibi ${ }^{*}$, Hiroto Tatamidani, and Kalyani Patil \\ Department of Chemistry, North Dakota State University, Fargo, North Dakota, 58105.
}

\section{Abstract}

Rhodium catalyzed conjugate addition of an aryl boronic acid to $\alpha$-methylamino acrylates followed by enantioselective protonation of the oxa- $\pi$-allylrhodium intermediate provides access to aryl substituted $\beta^{2}$-amino acids. The impact of the different variables of the reaction on the levels of enantioselectivity has been assessed.

Rhodium catalyzed conjugate addition of organoboron, ${ }^{1}$ organosilicon, ${ }^{2}$ and organotin ${ }^{3}$ reagents to $\alpha, \beta$-unsaturated systems has seen tremendous advances in the past decade. Hayashi, Miyaura and others have developed highly efficient enantioselective protocols for these conjugate additions that allows for the establishment of a new chiral center at the $\beta$-carbon. ${ }^{4}$ In contrast, use of this strategy to establish a stereocenter at the $\alpha$-carbon has met with limited success. ${ }^{5}$ Recently several examples of enantioselective rhodium enolate protonations leading to enantioenriched $\alpha$-amino acids and succinates have been reported. ${ }^{6}$

Development of new methods for the synthesis of $\beta$-amino acids is important. ${ }^{7}$ There are a number of enantioselective methods for the synthesis of $\beta$-substituted- $\beta$-amino acids ( $\beta^{3}$-amino acids). ${ }^{8}$ In contrast, there are few methods for the synthesis of $\alpha$-substituted- $\beta$-amino acids $\left(\beta^{2}\right.$-amino acids) enantioselectively. ${ }^{7}$ This substitution pattern is of interest since it is present in naturally occurring amino acids as well as compounds with potential therapeutic value. ${ }^{9}$

We have recently developed a novel method for the synthesis of $\beta^{2}$-amino acids using free radical chemistry. ${ }^{10}$ The stereochemistry in these reactions was established by an enantioselective $\mathrm{H}$-atom transfer after conjugate radical addition. ${ }^{11}$ One deficiency of the $\mathrm{H}$ atom transfer methodology was the inability to incorporate aromatic groups into the targets. We surmised that a rhodium catalyzed conjugate addition of an aryl boronic acid to $\mathbf{1}$ followed by enantioselective protonation of the oxa- $\pi$-allylrhodium intermediate $\mathbf{2}^{1}$ could provide access to aryl substituted $\beta^{2}$-amino acids (Scheme 1). ${ }^{12}$ Recently Frost and co-workers have reported a racemic version of the transformation shown in Scheme 1. ${ }^{13}$ In this work we have evaluated several variables for the conversion of $\mathbf{1}$ to 3 including the nature of the proton source, chiral ligand, catalyst, nitrogen protecting group, and the ester substituent and report a reasonably efficient method for the synthesis of enantioenriched $\beta^{2}$-amino acids.

Our work began with the identification of an optimal rhodium catalyst for the addition of phenylboronic acid to compound $\mathbf{5 a}$ using BINAP as the chiral ligand and water as the proton source. Our initial choice of catalyst, ligand, and proton source was based on the work of Hayashi, ${ }^{14}$ Genet, ${ }^{6 \mathrm{a}}$ Reetz, ${ }^{6 \mathrm{~b}}$ and Frost. ${ }^{6 \mathrm{c}}$ Results from these experiments are presented in Table 1. The catalyst rhodium (acac)bisethylene complex gave good yield of the addition product with modest enantioselectivity (entry 1 ). The reactions were effective at $50{ }^{\circ} \mathrm{C}$. 
Increasing the reaction temperature to $100^{\circ} \mathrm{C}$ did not improve the selectivity. 15 Of the four other variants tested, the catalyst derived from rhodium hydroxide (entry 2) and rhodium chloride (entries 3 and 4) gave good yields but only modest selectivity.

With these results at hand, we set out to determine the optimal chiral ligand and proton source for the formation of 6a. Results from these experiments are presented in Table 2. Several different proton sources have been evaluated by Genet and co-workers in their work on the synthesis of $\alpha$-amino acids. ${ }^{6 a}$ In our experiments, three different proton sources and several commercially available phosphine ligands were evaluated. ${ }^{16}$ Changing the proton source from water to 2-methoxyphenol led to a decrease in yield of 6a. However, there was a large improvement in enantioselectivity (entry 1). ${ }^{17}$ This observation is similar to that made by Genet. ${ }^{6 \mathrm{a}}$ The use of 2 -acetylphenol as a proton source was very beneficial providing $\mathbf{6 a}$ in $84 \%$ yield and $77 \%$ ee (entry 2 ). Phthalimide, with a reasonably acidic $\mathrm{N}-\mathrm{H}$, was also functional as a proton source providing the highest ee for the product with moderate yield (entry 3 ). ${ }^{18}$ The chemical efficiency of the reaction was modest using tol-BINAP as a ligand but the selectivity was high (entries 4 and 5). Of the several other ligand/proton source combinations tested (entries 6-12), Synphos ${ }^{19}$ gave good levels of enantioselectivity (entries 11 and 12). More promising results were obtained using a bisphosphine, Difluorphos, recently introduced by Genet, ${ }^{20}$ as a ligand (entries 13-15). A combination of this ligand and phthalimide as the proton source gave the product in excellent chemical yield and enantioselectivity (entry 15).

Having identified an optimal ligand/proton source combination, we evaluated the effect of the nitrogen protecting group and the ester substituent on efficiency and selectivity (Table 3). These two variables had a significant impact on the course of the reaction. Changing the ester substituent from tert-butyl to others with a phthalimido nitrogen protoecting group led to either inefficient reactions or low selectivity (entries 1-4). Thus a bulky ester substituent is essential for obtaining high selectivity. Succinimide and tosyl protecting groups seem promising (entries 5 and 6).

We have carried out preliminarily work on the scope of the aryl boronic acid component in the enantioselective protonation experiments and these results are shown in Table 4. The reaction conditions which were found to be best for phenylboronoic acid addition was employed for these studies. In general, the enantioselectivity in these experiments were high (entries 1, 2, 4, 5 , and 6). However, the chemical yield for the reaction was variable. For example, while reaction with 4-methoxyphenylboronic acid was highly efficient (entry 4), reaction with 4methylphenylboronic acid gave the product in only $16 \%$ yield (entry 3 ). Of the different substrates evaluated, reaction with 2-naphthylboronic acid gave the highest chemical yield and enantioselectivity (entry 6).

The absolute stereochemistry of the enolate protonation product $\mathbf{6 a}$ derived from reaction with phenylboronic acid and phthalimide as a proton donor was determined to be $(S)$ by converting it into a known compound. ${ }^{21}$ A catalytic cycle as postulated by Hayashi and Miyaura ${ }^{1 b}$ appears to be operative in our experiments also. Genet observed a strong correlation between the level of enantioselectivity and the nature of the proton donor. ${ }^{6 a}$ A functionality capable of coordinating the rhodium which is located ortho to the proton donor was optimal in their work. In our experiments we suggest that phthalimide containing a carbonyl donor coordinates the rhodium and transfers a proton to the oxa- $\pi$-allyl complex. The present work and the prior results in the literature suggest that enantioselective rhodium enolate protonations require a proper matching of all the variables and development of a general protocol is yet to be achieved.

In conclusion, we have developed a reasonably practical method for the preparation of $\beta^{2}$ amino acids. Furthermore, we have also demonstrated that enantioselective rhodium enolate 
protonations can be carried out with good selectivity. The extension of the present protocol to more complex susbtrates is underway in our laboratory.

\section{Supplementary Material}

Refer to Web version on PubMed Central for supplementary material.

\section{Acknowledgment}

We thank the NSF and NIH for financial support of our research programs.

\section{References}

1. (a) Hayashi T, Takahashi M, Takaya Y, Ogasawara M. J. Am. Chem. Soc 2002;124:5052. [PubMed: 11982369] (b) Takaya Y, Ogasawara M, Hayashi T, Sakai M, Miyaura N. J. Am. Chem. Soc 1998;120:5579.

2. Mori A, Danda Y, Fujii T, Hirabayashi K, Osakada K. J. Am. Chem. Soc 2001;123:10774. [PubMed: 11674025]

3. (a) Oi S, Moro M, Ono S, Inoue Y. Chem. Lett 1998:83. (b) Oi S, Moro M, Ito H, Honma Y, Miyano S, Inoue Y. Tetrahedron 2002;58:91.

4. For recent reviews, see:(a) Hayashi T. Synlett 2001:879. (b) Hayashi T, Yamasaki K. Chem. Rev 2003;103:2829. [PubMed: 12914482] (c) Fagnou K, Lautens M. Chem. Rev 2003;103:169. [PubMed: 12517183]

5. For an example of addition to 1-nitrocyclohexene seeHayashi T, Senda T, Ogasawara M. J. Am. Chem. Soc 2000;122:10716.

6. (a) Navarre L, Darses S, Genet J-P. Angew. Chem., Int. Ed 2004;43:719. (b) Reetz MT, Moulin D, Gosberg A. Org. Lett 2001;3:4083. [PubMed: 11735590] (c) Chapman CJ, Wadsworth KJ, Frost CG. J. Organomet. Chem 2003;680:206. (d) Moss RJ, Wadsworth KJ, Chapman CJ, Frost CG. Chem. Commun 2004:1984.. For Co-mediated reduction/protonation: (e) Ohtsuka Y, Ikeno T, Yamada T. Tetrahedron: Asymmetry 2003;14:967.. Racemic reactions: (f) Chapman CJ, Frost CG. Adv. Synth. Catal 2003;345:353. (g) Huang T-S, Li C-J. Org. Lett 2001;3:2037. [PubMed: 11418043]

7. For a recent review see:Liu M, Sibi MP. Tetrahedron 2002;58:7991.. Also see:Juaristi E, Lopez-Ruiz H. Curr. Med. Chem 1999;6:983. [PubMed: 10519909]

8. (a) Davies HML, Venkataramani C. Angew. Chem., Int. Ed 2002;41:2197. (b) Eilitz U, Leßmann F, Seidelmann O, Wendisch V. Tetrahedron: Asymmetry 2003;14:189. (c) Duursma A, Minnaard AJ, Feringa BL. J. Am. Chem. Soc 2003;125:3700. [PubMed: 12656591] (d) Muñoz-Muñiz O, Juaristi E. Tetrahedron 2003;59:4223. (e) Lee H-S, Park J-S, Kim BM, Gellman SH. J. Org. Chem 2003;68:1575. [PubMed: 12585907] (f) Seebach D, Schaeffer L, Gessier F, Bindschädler P, Jäger C, Josien D, Kopp S, Lelais G, Mahajan YR, Micuch P, Sebesta R, Schweizer BW. Helv. Chim. Acta 2003;86:1852.

9. Cryptophycins:(a) Subbaraju GV, Golakoti T, Patterson GML, Moore RE. J. Nat. Prod 1997;60:302. [PubMed: 9090872] Biologically active $\beta$-peptides: (b) Werder M, Hauser H, Abele S, Seebach D. Helv. Chim. Acta 1999;82:1774.

10. Sibi MP, Patil K. Angew. Chem., Int. Ed 2004;43:1235.

11. For a recent reviews on enantioselective H-atom transfer, see:(a) Sibi MP, Manyem S, Zimmerman J. Chem. Rev 2003;103:3263. [PubMed: 12914498] (b) Sibi MP, Porter NA. Acc. Chem. Res 1999;32:163.. For examples of chiral Lewis acid mediated H-atom transfer, see: (c) Sibi MP, Asano Y, Sausker JB. Angew. Chem. Int. Ed 2001;40:1293. (d) Sibi MP, Sausker JB. J. Am. Chem. Soc 2002;124:984. [PubMed: 11829606]

12. For recent reviews on enantioselective protonations see:(a) Eames J, Weerasooriya N. Tetrahedron: Asymmetry 2001;12:1. (b) Duhamel L, Duhamel P, Plaquevent J-C. Tetrahedron: Asymmetry 2004;15:3653. Also see (c) Muñoz-Muñiz O, Juaristi E. Tetrahedron Lett 2003;44:2023.

13. Wadsworth KJ, Wood FK, Chapman CJ, Frost CG. Synlett 2004:2022.. For Heck reactions with $\alpha-$ methylamino acrylates see:Huck J, Receveur J-M, Roumestant M-L, Martinez J. Synlett 2001:1467.

14. Takaya Y, Ogasawara M, Hayashi T. Chirality 2000;12:469. [PubMed: 10824171] 
15. For example, reaction using $\mathrm{Rh}$ (acac)(ethylene) 2 complex at $100{ }^{\circ} \mathrm{C}$ gave the product in $66 \%$ yield and $42 \%$ ee. We have also observed that prolonged heating of the t-butyl ester at $100{ }^{\circ} \mathrm{C}$ leads to decomposition of the starting material.

16. JOSIPHOS = 1-[2-(diphenylphosphino)ferrocenyl $]$ ethyl dicyclohexyl phosphine; MethylBOPhoz = $(R)-N$-methyl- $N$-diphenylphosphino-1-[S-2-(diphenylphosphino)ferrocenyl]ethylamine);

SYNPHOS = [(5,6), (5',6')-bis(ethylenedioxy)biphenyl-2,2'-diyl $]$ bis(diphenylphosphine);

DIFLUORPHOS = [(4,4'-bi-2,2-difluoro-1,3-benzodioxole)-5,5'diyl $]$ bis(diphenylphosphine) .

17. The product does not racemize under the reaction conditions.

18. Increasing the amount of phthalimide did not lead to enhancement of the chemical yield or selectivity.

19. Jeulin S, Duprat de Paule S, Ratovelomanana-Vidal V, Genet J-P, Champion N, Dellis P. PNAS 2004;101:5799. [PubMed: 15031423]

20. Jeulin S, Duprat de Paule S, Ratovelomanana-Vidal V, Genet J-P, Champion N, Dellis P. Angew. Chem., Int. Ed 2004;43:320.

21. Guichard G, Abele S, Seebach D. Helv. Chim. Acta 1998;81:187. 


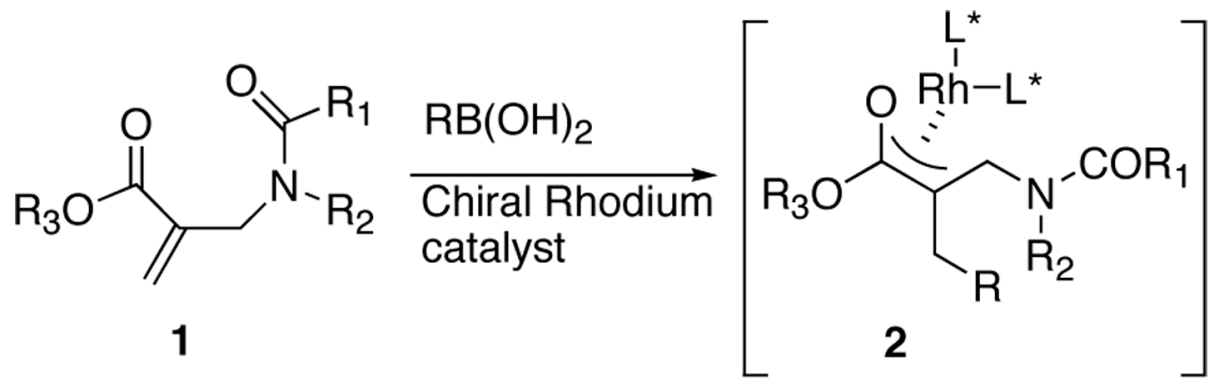<smiles>[R]CC(CN([R2])C([R])=O)C(=O)OC(=O)OCc1ccccc1</smiles>

3

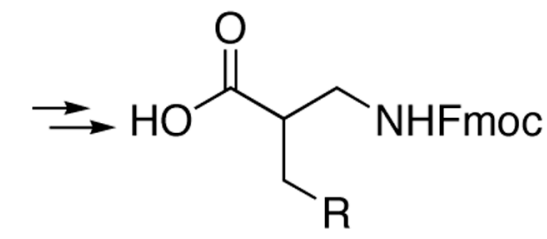

$4 \beta^{2}$-Amino Acid

Scheme 1. 
Table 1

Evaluation of Different Rhodium Complexes ${ }^{a}$

entry

${ }^{a}$ Isolated yields. Yields in parenthesis are for recovered starting materials.

${ }^{b}$ Chiral HPLC analysis; nd $=$ not determined. 
Table 2

Identification of Optimal Chiral Ligand and Proton Source for the conversion of $\mathbf{5 a}$ to $\mathbf{6 a}$.

\begin{tabular}{|c|c|c|c|c|}
\hline & $\begin{array}{l}\mathrm{PhB}(\mathrm{OH})_{2} \\
\text { Ligand } \\
\text { Rh(acac)(ethylene) } \\
2 \text { mol\% } \\
\stackrel{2 \text { dioxane, } 50^{\circ} \mathrm{C}, 20 \mathrm{~h}}{1 \text { eq proton source }}\end{array}$ & $\mathrm{Ph}$ & & \\
\hline entry & ligand & proton source $^{a}$ & yield, $(\mathrm{SM}) \%^{b}$ & ee, $\% c$ \\
\hline 1 & (S)-BINAP & 2-Methoxyphenol & $31(49)$ & 81 \\
\hline 2 & (S)-BINAP & 2-Acetylphenol & $84(2)$ & 77 \\
\hline 3 & (S)-BINAP & Phthalimide & $56(34)$ & 82 \\
\hline 4 & (S)-Tol-BINAP & 2-Methoxyphenol & $21(39)$ & 73 \\
\hline 5 & (S)-Tol-BINAP & 2-Acetylphenol & $42(40)$ & 77 \\
\hline 6 & (S,S)-DIOP & 2-Methoxyphenol & $43(31)$ & 36 \\
\hline 7 & (R,R)-CHIRAPHOS & 2-Methoxyphenol & $8(80)$ & nd \\
\hline 8 & (R,S)-JOSIPHOS & 2-Methoxyphenol & $0(95)$ & - \\
\hline 9 & (S)-MethylBOPhoz & 2-Methoxyphenol & $8(87)$ & nd \\
\hline 10 & (S)-SYNPHOS & 2-Methoxyphenol & $1(73)$ & nd \\
\hline 11 & (S)-SYNPHOS & 2-Acetylphenol & $30(67)$ & 71 \\
\hline 12 & (S)-SYNPHOS & Phthalimide & $25(50)$ & 70 \\
\hline 13 & (S)-DIFLUORPHOS & 2-Methoxyphenol & $8(83)$ & nd \\
\hline 14 & (S)-DIFLUORPHOS & 2-Acetylphenol & $71(15)$ & 88 \\
\hline 15 & (S)-DIFLUORPHOS & Phthalimide & $91(0)$ & 88 \\
\hline
\end{tabular}

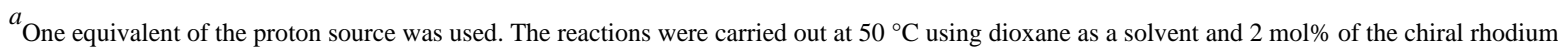
catalyst.

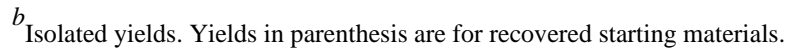

${ }^{c}$ Chiral HPLC analysis; nd $=$ not determined. 


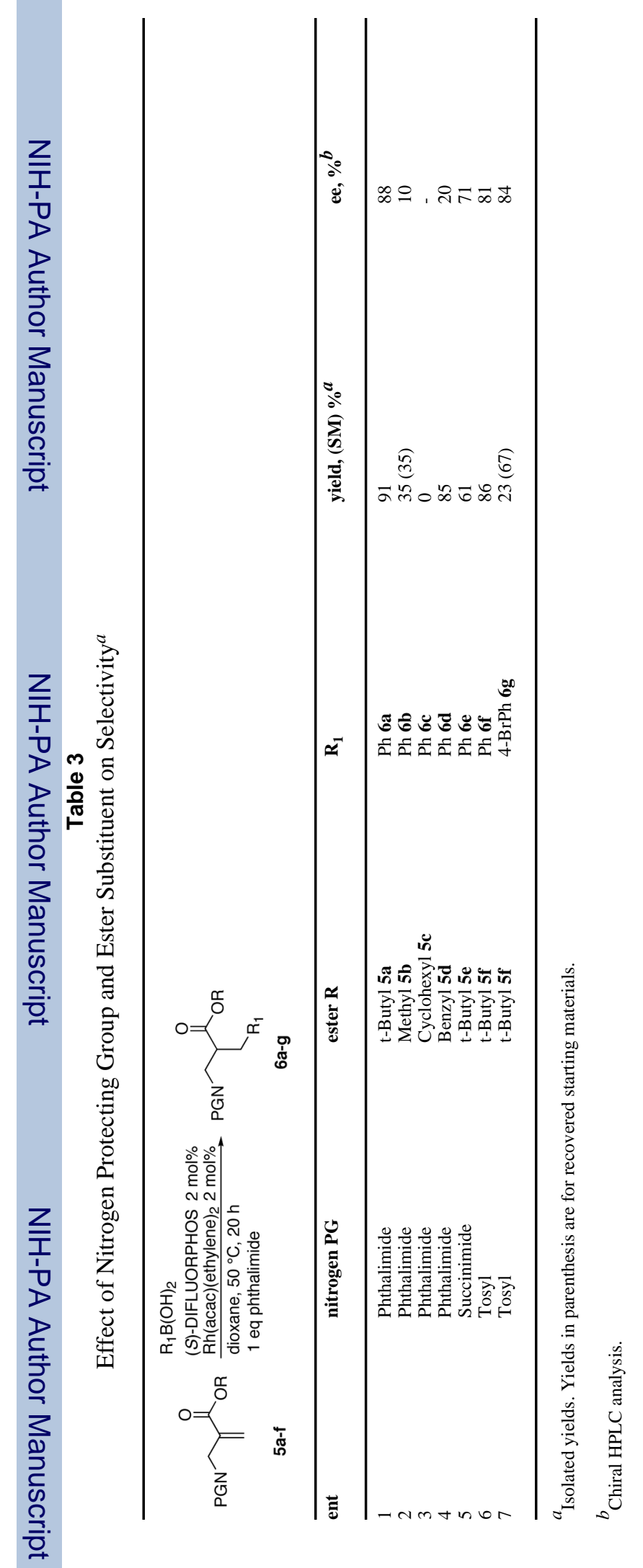

Org Lett. Author manuscript; available in PMC 2008 December 5. 


\section{Table 4}

Preparation of Different $\beta^{2}$-Amino Acids

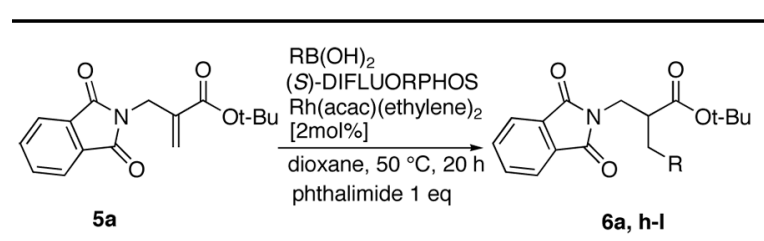

\begin{tabular}{|c|c|c|c|}
\hline entry & $\mathbf{R}$ & yield, $(\mathrm{SM}) \%^{a}$ & ee, $\%^{b}$ \\
\hline 1 & Phenyl 6a & 91 & 88 \\
\hline 2 & 4-Chlorophenyl $\mathbf{6 h}$ & $71(10)$ & 84 \\
\hline 3 & 4-Methylphenyl 6i & $16(62)$ & 63 \\
\hline 4 & 4-Methoxyphenyl $\mathbf{6 j}$ & 84 & 86 \\
\hline 5 & 3,5-Bistrifluoromethylphenyl $\mathbf{6 k}$ & $70(23)$ & 90 \\
\hline 6 & 2-Naphthyl 61 & 95 & 91 \\
\hline
\end{tabular}

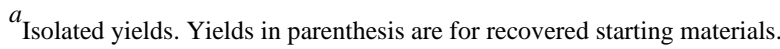

${ }^{b}$ Chiral HPLC analysis. 